\title{
The burden of osteoporotic hip fractures in Portugal: costs, health related quality of life and mortality
}

\author{
A. Marques $^{1}$ - Ó. Lourenço ${ }^{2}$. J. A. P. da Silva ${ }^{1,3}$ • on Behalf of the Portuguese Working \\ Group for the Study of the Burden of Hip Fractures in Portugal
}

Received: 2 February 2015 / Accepted: 7 May 2015

(C) International Osteoporosis Foundation and National Osteoporosis Foundation 2015

\begin{abstract}
Summary The study rationale was to provide a detailed overview of the costs, quality of life and mortality of hip fractures in Portugal. Mean individual fracture-related costs were estimated at $€ 13,434[12,290 ; 14,576]$ for the first year and $€ 5985$ [4982; 7045] for the second year following the fracture.

Introduction Osteoporotic fractures represent a remarkable burden to health care systems and societies worldwide, which will tend to increase as life expectancy expands and lifestyle changes favour osteoporosis. The cost-effectiveness evaluation of intervention strategies demands accurate data on the epidemiological and economical reality to be addressed.

Methods Information was collected retrospectively on consumption of resources and changes in quality of life attributable to fracture as well as mortality, regarding 186 patients randomly selected to represent the distribution of hip fractures in the Portuguese population, in terms of gender, age and geographical provenience. Data were cross-tabulated with socio-demographic variables and individual resource consumption to estimate the burden of disease. A societal perspective was adopted, including direct and indirect costs.
\end{abstract}

Electronic supplementary material The online version of this article (doi:10.1007/s00198-015-3171-5) contains supplementary material, which is available to authorized users.

A. Marques

amarques@reumahuc.org

1 Rheumatology Department, Centro Hospitalar Universitário de Coimbra, 3000-075 Coimbra, Portugal

2 Centro de Estudos e Investigação em Saúde da Universidade de Coimbra, Faculty of Economics, University of Coimbra, Av. Dias da Silva, 1653004-512 Coimbra, Portugal

3 Faculty of Medicine, University of Coimbra, Coimbra, Portugal
Multivariate analyses were carried out to assess the main determinants of health-related quality of life (HrQoL).

Results Mean individual fracture-related costs were estimated at $€ 13,434[12,290 ; 14,576]$ for the first year and $€ 5985$ [4982; 7045] for the second year following the fracture. In 2011 the economic burden attributable to osteoporotic hip fractures in Portugal could be estimated at $€ 216$ million. Mean reduction in HrQoL 12 months after fracture was estimated at 0.34 . Regression analysis showed that age was associated with a higher loss of HrQoL, whereas education had the opposing effect. We observed $12 \%$ excess mortality in the first year after hip fracture, when compared to the gender and age-matched general population.

Conclusions Results of this study indicate that osteoporotic hip fractures are, also in Portugal, despite its low incidence of fractures and cost per event, associated with a high societal burden, in terms of costs, loss in HrQoL and mortality. These data provide valuable input to the design and selection of fracture prevention strategies.

Keywords Costs $\cdot$ Fracture $\cdot$ Mortality $\cdot$ Osteoporosis · Quality of life

\section{Introduction}

Osteoporotic fractures impact an enormous burden upon societies due to costs related to immediate treatment and also to the management of their long-term consequences in terms of disability, comorbidity and mortality.

It has been estimated that the annual number of osteoporotic fractures in the European Union will rise from 3.5 million in 2010 to 4.5 million in 2025, corresponding to an increase of $28 \%$ [1]. The annual worldwide direct and indirect costs of 
hip fractures have been calculated at $\$ 34.8$ billion in 1990 and are expected to rise to an estimated $\$ 131$ billion by 2050 [2].

This burden and its prospected increase impose the need for careful evaluation of the cost-effectiveness of different intervention strategies. These strategies need to be adapted to the actual epidemiological and economical reality that they intend to address, as it can be quite diverse [3]. Portugal has a relatively low incidence of osteoporotic hip fractures at around 206 cases per 100,000 population aged 40+ [4]. The management of osteoporotic fractures, as well as the cost of treatment, can also vary [5].

Hip fractures are a useful surrogate for determining the overall burden of osteoporosis, as they are more readily identified in hospital discharge registers. Studies performed in countries with reliable registers of all types of fractures are typically used to extrapolate from data obtained with hip fractures [1]. However, detailed cost-of-illness (COI) studies regarding hip fractures must be performed in each country if locally valid guidance and conclusions are to be drawn.

To the extent of our knowledge, this is the first study to estimate the overall societal cost of hip fractures, the perpatient costs and the impact on heath-related quality of life in Portugal, based on real-life individual patient data.

\section{Methods and material}

In this study, we adopt a prevalence-based approach time [6]. We took a societal perspective in the measurement of costs [6]. Data on resource consumption over the 2 years following the fracture were collected retrospectively regarding fractures that occurred 24 to 30 months before the interview. Patients themselves or their primary caregivers provided the information. By 'primary caregiver', we mean the person responsible for managing the care of the patient, i.e. the family member or trained professional who took care of medication, personal support and medical appointments throughout the 2 years of interest. If such a person could not be clearly identified, the patient was excluded and another one recruited.

A draft version of the questionnaire was tested in ten individuals and adaptive corrections were introduced into the final version, as recommended [7, 8]. The first part of the questionnaire covered patient socio-demographic data and the quantities of resources consumed over the 2-year period following fracture or until death. The second part of the questionnaire aimed to assess the patients' health-related quality of life (HrQoL). We used the EQ-5D instrument in the version validated for the Portuguese population that contain a Portuguese tariff [9]. These questions were focused onto three different moments: (1) before the hip fracture, (2) 1 month after the fracture and (3) 1 year after the fracture. The interviews were conducted by telephone by three trained interviewers (AM; IL; JS) and took, on average, $25 \mathrm{~min}$. Participants were asked to identify solely expenses incurred as a consequence of fracture and none other.

The resources consumed by patients were categorised into direct medical costs (inpatient care, rehabilitation care, outpatient consultations, osteoporosis preventive medications, diagnostic tests and nursing care) and direct non-medical costs (long-term care, nursing home, patient's transportation, technical aids, home adaptations, home care, informal care and burial) as performed by several authors [3, 7, 10, 11]. Costs associated with productivity changes due to the hip fracture were also included in the analysis [12]. Information regarding the definition of resources and their unit cost is provided in Supplementary Material (Table 1).

Participation was explicitly voluntary and ethical approval was obtained from the Ethical Committee of the Faculty of Medicine of Coimbra University.

\section{Power calculations}

In the calculations for the sample size, performed to establish the minimum number of patients required to ensure reliability of the national estimates of the mean cost per fracture, we decided to assume a range of total costs between $€ 2500^{1}$ and $€ 20,000^{2}$ for the first year, thus deriving an estimate of the SD of about $4375 .^{3}$ Establishing an absolute maximum error of estimation on $€ 800,{ }^{4}$ not to be exceeded with higher than $5 \%$ probability, the sample size required is 114 units. ${ }^{5}$ Due to the uncertainty in the population's SD estimate, we planned to include 186 patients (details on the statistical calculations employed can be found on references [13, 14].

\section{Patient selection}

We obtained demographic information about all osteoporotic hip fractures treated in Portuguese public hospitals in the year 2011, through the National Hospital Discharge Register. Public hospitals are estimated to take care of over $95 \%$ of all osteoporotic hip fractures in Portugal. Based on the observed cases, we designed a stratified random sampling method-the size of the sample in each stratum was proportionate to the size of the stratum in the population. We defined the

\footnotetext{
${ }^{1} € 2500$ corresponds to the comprehensive cost of inpatient care to treat a hip fracture. Table 1 shows the source of this figure. ${ }^{2} € 20,000$ corresponds approximately to the upper $95 \%$ confidence interval for Sweden [7], assuming the replacement costing method.

${ }^{3}$ [13] refers that and estimate of the SD can be found by computing the range divided by 4 .

${ }^{4} € 800$ is approximately equivalent to $5 \%$ of the mean cost of hip fracture in Sweden [7] assuming the replacement cost method ${ }^{5}$ The sample size estimation accounted for fact that we are extracting a random sample from a finite population.
} 
following strata: geographical origin, gender and the age groups $\leq 74,75$ to 85 , and $\geq 85$ years. Twenty-six hospitals in Portugal mainland were selected and invited to collaborate in the study. Each hospital was requested to recruit a number of cases per strata proportionally equivalent to its representation in the national hip fracture case list 2011.

A representative from each hospital, typically the head of the orthopaedics department, was asked to provide the contact of a pre-defined number of consenting patients of specific age $\times$ gender combination. These participants were randomly selected from within the full list of hip fracture victims locally treated in 2011, following a web-based random number generator. There were no exclusion criteria. Even patients who had died or were unable to answer were included if the primary caregiver remains the same over all the period of study. To decrease the likelihood of refusals and respect the principles underlying the ethical approval, the local hospital representative contacted directly the patient or caregiver, presented the goals of the project and asked for permission (consent) for a subsequent phone enquiry by the research team. In total, 212 individuals were selected according to these criteria. Twentysix were excluded because of difficulties in contact $(n=13)$, refusal $(n=9)$ and unavailability or undefinition of primary caregiver $(n=4)$. We confirmed that five of these twenty-six patients had died since the fracture.

\section{Statistical analysis}

Information is summarized as arithmetic means with $95 \%$ confidence intervals (CIs) or percentages as appropriate. When informative, we also display the standard deviation of some statistics. Student's $t$ tests were conducted to compare means and two-proportion $z$ test was adopted compare proportions.

The expected number of deaths in our sample was estimated on the basis of national gender and age-specific mortality rates. Our data contain the number of days until death after the hip fracture, we use these data to estimate the survival, and to compare across groups, we use the log-rank test [15].

A multiple linear regression model was used to analyse the relationship between $\mathrm{HrQoL}$ and a set of potentially relevant independent variables. Further information regarding the definition of all variables and the methodology used in the regression models can be found in the "Supplementary Material". All statistical analyses were conducted using Stata, version 12.0.

\section{Results}

We collected data from 186 patients. Demographic characteristics of participants are presented in Table 1. Mean age at fracture was 80.5 years and $78.5 \%$ of the respondents were female. These data, as well as the geographical distribution, correspond almost perfectly to the parameters of the total population that
Table 1 Summary of patient demographics

\begin{tabular}{llc}
\hline Total & & $186(=100 \%)$ \\
\hline Gender, $N(\%)$ & Female & $146(78.5)$ \\
& Male & $40(21.5)$ \\
Age, $N(\%)$ & $\leq 74$ & $36(19.4)$ \\
& $\geq 75<85$ & $92(49.4)$ \\
& $\geq 85$ & $58(31.2)$ \\
Marital status, $N(\%)$ & Married & $77(41.4)$ \\
& Divorced & $8(4.3)$ \\
& Single & $14(7.5)$ \\
Residence prior to fracture & Widowed & $87(46.8)$ \\
& Own house & $159(85.5)$ \\
& With relatives & $19(10.2)$ \\
Year of formal education, $N(\%)$ & Nursing home & $8(4.3)$ \\
& $=0$ & $35(18.8)$ \\
& $\geq 0 \leq 4$ & $131(70.4)$ \\
& $>4$ & $20(10.8)$ \\
\hline
\end{tabular}

suffered hip fractures in Portugal over the year 2011 (total $N=$ 11,124 , mean age $80.5 \pm 9.9$ years and $76 \%$ female, differences not statistically significant). On average, these patients had attended school for 3.5 years (SD 2.82). Prior to fracture, $85.5 \%$ resided on their own house, $10.2 \%$ lived with relatives, and $4.3 \%$ already resided in a nursing home.

\section{Resource use and costs}

Table 2 presents the proportion of patients who used each type of resource as a consequence of the hip fracture. The likelihood of utilization of each type of resource is much higher during the first year following the facture than in the second year. Further to hospital admission, nearly $100 \%$ visited a physician at least once and used diagnostic tests. Technical aids were purchased by $85 \%$ of patients, transportation by ambulance was used by $75.8 \%$, and $61.8 \%$ received rehabilitation care. Only $29.6 \%$ were treated with calcium and/or vitamin $\mathrm{D}$, and $16.7 \%$ received other anti-osteoporotic agents within the 2 years following the fracture. After discharge from hospital, $18.3 \%$ of the patients were transferred to a long-term care facility and $19.9 \%$ to a nursing home; $18.3 \%$ of the patients needed home care support and $32.3 \%$ receive care from a nurse. During the second year, there was a marked decrease of the variety and quantity of resources used: no consumption of nursing care, technical aids, diagnostic tests and transportation were reported as due to the hip fracture in the second year. Regarding family and friends' support, $62.9 \%$ of patients reported receiving an average of $32.9 \mathrm{~h}$ by week of this type of care, as a consequence of the fracture, during the first year. Productivity losses were only reported by four patients - all the remaining participants were already retired. 
Table 2 Patients making use of specific resources, due to hip fracture, by year of consumption: percentage $(n)$

\begin{tabular}{lcl}
\hline Resource & Year 1 $(n=186)$ & Year 2 $(n=148)$ \\
\hline Rehabilitation care & $61.8(115)$ & $8.06(12)$ \\
Inpatient care & $100(186)$ & $2.15(3)$ \\
Medical consultations & $97.3(181)$ & $45.9(70)$ \\
Osteoporosis treatment & $16.7(31)$ & $16.7(25)$ \\
Calcium+vitamin D & $29.6(55)$ & $29.6(44)$ \\
Diagnostic tests (X-ray/densitometry/ & $98.4(183)$ & 0 \\
$\quad$ CT scan) & $32.3(60)$ & 0 \\
Nursing care & $18.3(34)$ & $0.5(1)$ \\
Long-term care & $19.9(37)$ & $15.5(23)$ \\
Nursing home & $18.3(34)$ & $14.5(21)$ \\
Home care & $85(158)$ & 0 \\
Technical aids & $75.8(141)$ & 0 \\
Transportation & $62.9(117)$ & $41.4(61)$ \\
Informal care & $2.15(4)$ & 0 \\
Productivity losses &
\end{tabular}

Table 3 presents an estimate of the cost $(€)$, per patient and per year, for each type of resource considered, stratified by gender. Considering all resources, the average cost per patient, per year, for treating a hip fracture in Portugal is estimated at $€ 13,434$ for the first year and in $€ 5985$ for the second year after the hip fracture. With reference to the first year, $28 \%$ of the total costs are due to direct medical costs, $70 \%$ due to direct non-medical costs and the remaining $2 \%$ are indirect costs due to productivity losses. During the second year, there is a marked decrease of costs, the most relevant item being informal care (€3549). Participants did not report any costs associated with transportation or technical aids in the second year. The productivity loss cost category was only verified in four men and contributed an average of $€ 194$ for the total cost of each hip fracture.

We verified that variable type of respondent (caregiver/patient) does not have a significant influence upon costs or quality of life in the multivariate regression analysis. Data are not shown.

Taking into account the 11,124 hip fractures that occurred in year 2011 in mainland Portugal, the total societal cost for the first year of treatment was estimated at $€ 149$ million. Direct medical costs, direct non-medical costs and indirect costs represent approximately $28.4,70.2$ and $1.4 \%$ of this value, respectively. This total value must be added to $€ 66$

Table 3 Costs in euros, per patient and per year, for each type of resource considered

\begin{tabular}{|c|c|c|c|c|c|c|}
\hline & Year 1 & Year 2 & Year 1 female & Year 1 male & Year 2 female & Year 2 male \\
\hline \multicolumn{7}{|l|}{ Direct medical costs } \\
\hline Rehabilitation care & $1056[845 ; 1266]$ & $179[73 ; 285]$ & $1040[799 ; 1281]$ & $1115[666 ; 1563]$ & $168[61 ; 275]$ & $221[-94 ; 537]$ \\
\hline Inpatient care & 2500 & $67[8 ; 125]$ & 2500 & 2500 & $51[-6 ; 110]$ & $125[-51 ; 301]$ \\
\hline Medical consultations & $145[127 ; 162]$ & $47[34 ; 59]$ & $147[127 ; 168]$ & 136 [104; 169] & $50[35 ; 65]$ & $30[6 ; 53]$ \\
\hline Osteoporosis treatment & $54[43 ; 66]$ & $54[43 ; 66]$ & $61[47 ; 74]$ & $30[12 ; 48]$ & $61[47 ; 74]$ & $30[12 ; 48]$ \\
\hline $\begin{array}{l}\text { Diagnostic tests (X-ray/ } \\
\text { densitometry/CT scan) }\end{array}$ & $31[26 ; 35]$ & 0 & $30[26 ; 34]$ & $34[18 ; 50]$ & 0 & 0 \\
\hline Nursing care & $32[24 ; 40]$ & 0 & $31[21 ; 40]$ & $36[20 ; 52]$ & 0 & 0 \\
\hline Total direct medical costs & $3818[3603 ; 4046]$ & $347[210 ; 484]$ & 3809 [3569-4072] & 3851 [3397; 4304] & $330[192-450]$ & $406[-18 ; 849]$ \\
\hline \multicolumn{7}{|l|}{ Direct non-medical costs } \\
\hline Long-term care & $982[606 ; 1357]$ & $172[-167 ; 510]$ & $1008[568 ; 14479]$ & $887[166 ; 1607]$ & $219[-214 ; 652]$ & 0 \\
\hline Nursing home & $1383[939 ; 1828]$ & $1114[696 ; 1533]$ & 1299 [804; 1794] & $1691[647 ; 2734]$ & $970[535 ; 1406]$ & $1640[487 ; 2792]$ \\
\hline Home care & $855[477 ; 1232]$ & $803[431 ; 1175]$ & $916[467 ; 1364]$ & $632[-31 ; 1295]$ & $850[408 ; 1291]$ & $632[-31 ; 1295]$ \\
\hline Technical aids & $588[395 ; 781]$ & 0 & $599[368 ; 830]$ & $548[220 ; 876]$ & 0 & 0 \\
\hline Transportation & $74[48 ; 101]$ & 0 & $71[43 ; 100]$ & $86[20 ; 153]$ & 0 & 0 \\
\hline Burial $^{\mathrm{a}}$ & $149[90 ; 208]$ & 0 & $163[94 ; 233]$ & $94[-12 ; 201]$ & 0 & 0 \\
\hline Informal care & $5391[4429 ; 6352]$ & 3549 [2718; 4379] & 5628 [4524; 6732] & $4523[2519 ; 6525]$ & $3870[2889 ; 4851]$ & $2375[919 ; 3832]$ \\
\hline $\begin{array}{l}\text { Total direct non-medical } \\
\text { costs }\end{array}$ & $\begin{array}{l}9422 \\
{[8339 ; 10,504]}\end{array}$ & $\begin{array}{l}5638 \\
{[4658 ; 6618]}\end{array}$ & $\begin{array}{l}9684 \\
{[8452 ; 10,935]}\end{array}$ & $\begin{array}{l}8461 \\
{[6162 ; 10,696]}\end{array}$ & $\begin{array}{l}5909 \\
{[4785 ; 7035]}\end{array}$ & $\begin{array}{l}4647 \\
{[2606 ; 6688]}\end{array}$ \\
\hline Productivity loss & $\begin{array}{l}194 \\
{[-16 ; 405]}\end{array}$ & 0 & 0 & $\begin{array}{l}904 \\
{[-77 ; 1885]}\end{array}$ & 0 & 0 \\
\hline Total costs & $\begin{array}{l}13,434 \\
{[12,290 ; 14,576]}\end{array}$ & $\begin{array}{l}5985 \\
{[4982 ; 7045]}\end{array}$ & $\begin{array}{l}13,493 \\
{[12,187 ; 14,814]}\end{array}$ & $\begin{array}{l}13,216 \\
{[10,782 ; 15,586]}\end{array}$ & $\begin{array}{l}6239 \\
{[5131 ; 7476]}\end{array}$ & $\begin{array}{l}5053 \\
{[5131 ; 7476]}\end{array}$ \\
\hline
\end{tabular}

The intervals in each cell represent the $95 \%$ confidence interval

${ }^{\text {a }}$ Only the costs of burials due to excess mortality were computed 
million for the second year of care. Altogether, the cost of osteoporotic hip fractures can be estimated at approximately $€ 216$ million per year at current costs.

\section{Mortality}

Altogether, 50 (26.9\%) of the 186 patients included in this study died within 2 years of suffering the hip fracture. Thirtyeight of the deaths occurred in the first year (mortality rate $20.4 \%$ ) and 12 in the second (mortality rate of $8.1 \%, 12$ / 148). Using Portuguese life tables [16], we estimated the expected yearly mortality for the general population, of similar age and gender composition, to be approximately $8.6 \%$. Thus, our data demonstrate that an excess of mortality is observed in association with hip fracture within the first 12 months after the fracture, being nullified in the second year and presumably thereafter.

On this basis, we estimate that a total of 2272 deaths will have occurred in Portugal following the 11,124 hip fractures observed in 2011, as opposed to the 962 expected in that population. Therefore, we conclude that probably around 1310 excess deaths occur every year as a consequence of hip fractures.

The survival functions were not significantly influenced by either gender $(p=0.47)$ or education (categorized in four levels, $p=0.98$ ) or age (categorized into three age groups $p=$ 0.15 ), according to the log-rank test.

\section{Quality of life}

The mean pre-fracture HrQoL score was 0.65 (95\% CI [0.63, $0.69])$. Values for males and females were very similar to the reference for the Portuguese population of similar age [9] ( 0.68 vs 0.67 for men; 0.65 vs 0.56 for women).

One month after the fracture, the HrQoL decreased markedly to -0.18 (95\% CI $[-0.22,-0.15])$. A two-sample paired Student's t-test clearly rejected the hypothesis of equal HrQoL before and after the fracture $(p<0.001)$. One year after the fracture, patients partially recovered $\mathrm{HrQoL}$, the average being, by then, 0.29 (95\% CI [0.22, 0.36]).

Figure 1 shows health utility measured using the EQ-5D before, 1 month after and 1 year after the hip fracture. On average, women report lower HrQoL scores than males, but the differences observed did not reach statistical significance.

\section{Factors influencing quality of life}

We performed multivariate regression analysis to analyse whether short and long-term relative losses and 1-year recovery of $\mathrm{HrQoL}$, as defined in Table 2 of the Supplementary Material, are associated with specific individual characteristics. Results are presented in Table 4. In all models, the disturbances were found to be homoskedastic by the Breusch-
Pagan/Cook-Weisberg test, and no multicollinearity problems were found.

None of the covariates included in the model demonstrated to be relevant in explaining the short-term relative loss of HrQoL. Regarding long-term impact, the data show that the covariates 'age' and 'level of education' have a statistically significant impact upon relative loss of $\mathrm{HrQoL}$ at 1 year after fracture. Age is associated with higher long-term relative loss. On the other hand, longer duration of formal education is associated with a lower relative loss of HrQoL.

The covariates age $(-0.008)$ and being transferred to a long-term care facility after the fracture $(-0.471)$ were negatively associated with the 1 -year recovery variable. Females, those with more years of education and those who received physiotherapy after fracture recovered, on average, more HrQoL 1 year after the fracture than their counterparts.

\section{Discussion}

The objective of this investigation was to estimate the total annual cost of osteoporotic hip fractures to the Portuguese society, the per-patient costs and the impact of these fractures upon patients' HrQoL and life expectancy. We estimated that the total cost of the osteoporotic hip fractures in Portugal, in 2011, was nearly $€ 216$ million with a per-patient cost of $€ 13$, 434 in the first year and $€ 5985$ in the second year following fracture. Direct non-medical costs represent over $70 \%$ of the overall expenditure. Indirect costs related with loss of productivity were marginal given the average age of the affected population. Higher age is associated with higher per-patient costs. This represents a very important burden upon the national health budget even if the absolute values are much lower than in northern European countries where both the incidence of fracture and their individual cost are much higher than in Portugal $[5,11,17,18]$.

Our results demonstrate that a hip fracture has a major impact on the individuals' HrQoL, which persists for at least 1 year. The EQ-5D scores were at baseline, in our sample, similar to the reference values for the age- and gendermatched Portuguese population. The average HrQoL at 1 month after fracture was rated at levels equivalent to "worse than death'. At 1 year, there was considerable recovery of $\mathrm{HrQoL}$, but it still persisted significantly below baseline levels. The impact of HrQoL at 1 year is increased with increasing age and reduced in relation to higher levels of education.

Hip fractures in Portugal are associated with significant mortality: $26.9 \%$ of the victims had died within 2 years after fracture. This represents an excess of about $12 \%$ in observed versus expected mortality, which is observed almost exclusively in the first year after fracture. Altogether, we estimate 
Fig. 1 EQ-5D score before, one month after and one year after fracture, by gender, and the age matched references for the Portuguese population [9]

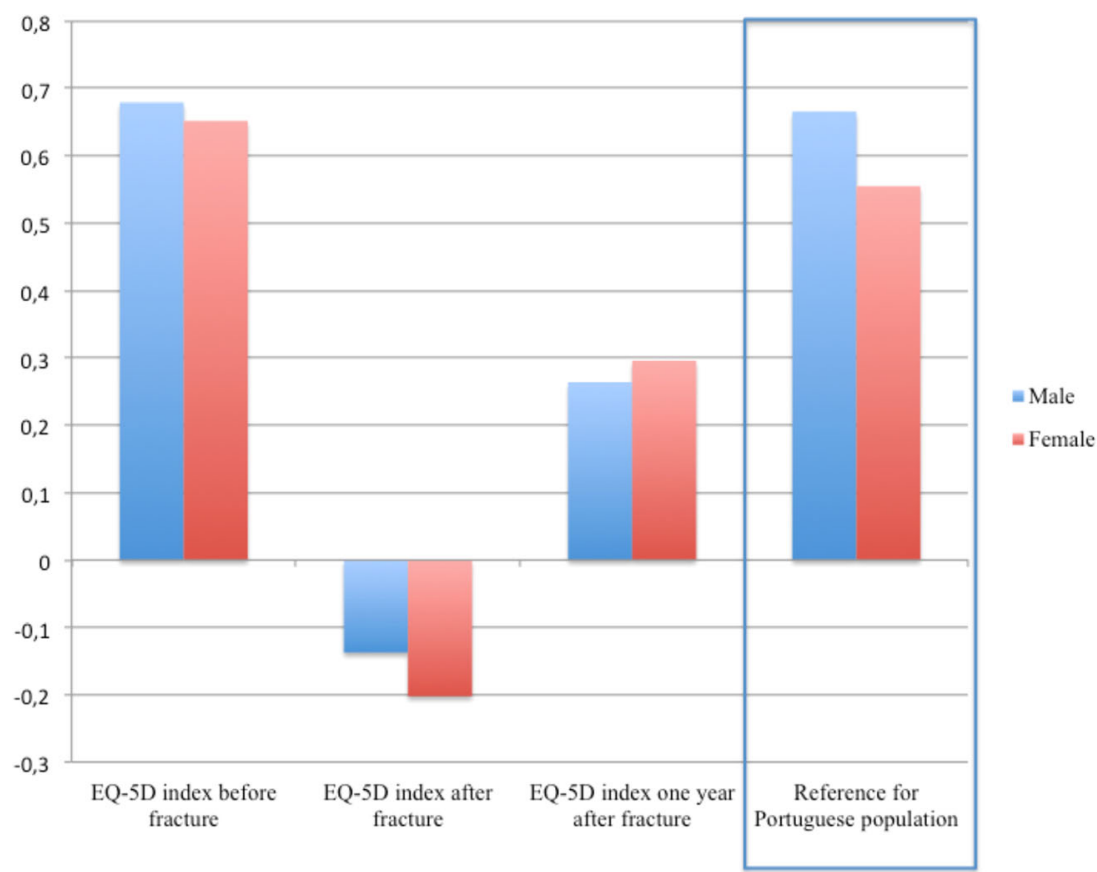

that hip fractures observed in Portugal during the year 2011 were responsible for an excess of over 1310 deaths. Excess mortality attributable to fractures and its cost probably need to be down-adjusted given that patients who sustain a hip fracture are, on average, frailer than the general population. However, as there is no solid basis to quantify this adjustment, we decide to present absolute numbers and underline this potential limitation. On the other hand, given that the excess mortality occurs mostly on the first year, it will tend to reduce other costs associated with care of the surviving patient with fracture.
To the best of our knowledge, this is the first study to collect individual-level data regarding the cost of osteoporotic hip fractures in Portugal. The results confirm that hip fractures represent a relevant socio-economic burden to the individual, family, health services and society in Portugal.

Comparisons of results obtained with cost of illness studies should be made with caution, as both the reality under evaluation and the methodology employed can vary considerably.

The total societal cost of one hip fracture estimated by our study is similar to that reported for most other developed countries. For example, the per-patient fracture-related cost,

Table 4 Predictors of relative loss of HrQoL following hip fracture and its recovery

\begin{tabular}{|c|c|c|c|c|c|c|}
\hline & \multicolumn{2}{|c|}{ Short-term relative loss } & \multicolumn{2}{|c|}{ Long-term relative loss } & \multicolumn{2}{|c|}{ 1-year recovery (absolute values) } \\
\hline & $B$ & $p$ value & $\beta$ & $p$ value & $\beta$ & $p$ value \\
\hline Female & 0.113 & 0.26 & 0.012 & 0.93 & 0.159 & $0.05^{*}$ \\
\hline Age & -0.001 & 0.93 & 0.019 & $0.03 *$ & -0.008 & $0.05^{*}$ \\
\hline Married & 0.101 & 0.40 & -0.113 & 0.59 & 0.105 & 0.35 \\
\hline Level of education & 0.001 & 0.98 & -0.081 & $0.001 *$ & 0.024 & $0.04 *$ \\
\hline Living alone before & 0.008 & 0.94 & -0.127 & 0.54 & -0.069 & 0.52 \\
\hline Nursing home before & 0.097 & 0.57 & -0.022 & 0.95 & 0.080 & 0.70 \\
\hline Physiotherapy & - & - & -0.001 & 0.54 & 0.002 & $0.01 *$ \\
\hline Living alone after & - & - & -0.229 & 0.21 & 0.236 & $0.02 *$ \\
\hline Nursing home after & - & - & 0.390 & 0.06 & -0.120 & 0.24 \\
\hline Long-term care after & - & - & 0.655 & 0.08 & -0.477 & $0.01 *$ \\
\hline$R^{2}$ & 0.02 & & 0.17 & & 0.25 & \\
\hline
\end{tabular}

$\beta$ regression coefficient

* Statistically significant 
per year, after a hip fracture was estimated at $€ 16,379$ in the Netherlands in 2014 [18], €14,221 in Sweden, by 2006 [11], and $€ 13,205$ in the USA in 2013 [17]. Reported costs in China are considerably lower: $€ 3177$ [10]. Discrepancies between these estimates seem to be essentially due to difference in costs per unit of care, rather than consumption of resources. It is quite possible that our total costs are underestimated by the use of the national tariff for services provided in the Portuguese NHS, which are commonly considered underpriced. On the other hand, we have considered costs that are frequently ignored by studies in this area, such as the cost of burial and of informal care. In support of this approach, we would argue that death is associated with a direct cost of its own which should be appropriately considered as a nonmedical direct cost. Similarly, the care provided by family and friends would have to be provided by someone in their absence and therefore represents a societal cost, even if it is endured by family and/or friends. We have only accounted for the costs of excessive number of deaths probably due to hip fractures $(12 \%)$ and attributed to informal care the cost equivalent to our current national minimum wage, $€ 505 /$ month.

The percentage of patients undergoing treatment for osteoporosis with specific agents $(16.7 \%)$ or with calcium plus vitamin D (29.6 \%) after hip fracture is worryingly small. These percentages are nevertheless in line with international results $[7,10,17,19]$ and emphasize the urgent need for strategies to improve the management of osteoporosis after fracture.

We identified that $17.8 \%$ of women and $20 \%$ of men living in the community at the time of fracture entered a long-term care facility and that $18.5 \%$ of women and $25 \%$ of men were admitted to a nursing home during the first year after fracture. These values are in agreement with previous studies and demonstrate that loss of independence after hip fracture is a critical problem for these patients and for society $[16,20,21]$.

The results presented here support previous research demonstrating that hip fractures are associated with a substantial decrement in HrQoL [11, 22-24]. In a systematic review, hip fractures were associated with a HrQoL decrement of approximately $50 \%$ shortly after fracture and $20 \% 4$ months after fracture [23]. In our study, HrQoL values are close to the estimates found in others studies, with the exception of HrQoL 1 month after the event, which is remarkably lower in our case. This difference may be related to the exact time of evaluation, as HrQoL changes rapidly under these circumstances. Cultural issues may also play a role [22].

Our results need to be viewed in the light of several positive aspects and also limitations. Among the positive aspects, we underline the representative nature of our sample, derived not only from its size but also from the random selection strategy ensuring a valuable similarity between our sample and the overall population in terms of age, gender and geographic provenience. We have adopted statistical methodologies of analysis that are well rooted in the literature of COI studies. Our limitations include the retrospective collection of data, which may have some negative impact on the precision of the results, although several authors and consensus groups defend that personal health information can be collected with reasonable precision if specific and pre-defined questions are employed $[25,26]$. We have carefully respected the ten main recommendations published by Matt et al. [27] to ensure a good collection of data in retrospective studies.

Baseline HrQoL could have been especially open to this problem as patients might perceive their baseline HrQoL to be better than it actually was, which could lead to an overestimation of the loss of HrQoL due to the fracture. However, the HrQoL scores described by our participants before fracture were very similar to the reference for the Portuguese population [9]. Our cost estimates may be underestimated for the use of national tariffs instead of market prices.

We opted to include all randomized patients even when the information could only be provided by a primary caregiver. Although this may be seen as a limitation, there is evidence that proxies can provide reliable information regarding EQ5D scores $[28,29]$ and resource utilization and costs of hip fractures [30-32], when patients are not able or available to do so. We also verified in a regression model if the type of respondent (caregiver/patient) influences the costs and quality of life, and this variable does not influence either costs or quality of life. Data are not shown.

\section{Conclusion}

The results of this study demonstrate that osteoporotic hip fractures represent an important cause of health resource consumption and overall societal cost in Portugal, despite its relatively low incidence in our country. Hip fractures have a marked negative effect on $\mathrm{HrQoL}$, which persists for at least 1 year, and a significant impact on mortality. It is expected that the costs and societal impact of osteoporotic hip fractures will rise with the projected increase of life expectancy and the feminization of the elderly population.

Further research is needed to evaluate the costeffectiveness of different strategies to prevent osteoporotic fractures and to limit their impact on the HrQoL and life expectancy of its victims.

Acknowledgments The authors acknowledge the elements of the Portuguese working group for the study of the burden of hip fractures in Portugal: Patrícia Pinto, Graça Sequeira, Pedro Abreu, Ana Façanha, Benjamin Rodrigues, Nuno Geada, Bruno Canilho, Rogério Barroso, José Franco, Henrique de Jesus, Gabriel Xavier, Sandra Sousa, Viviana Tavares, Pedro Cantista, Tiago Meirinhos, Luís Palma, Sandra Martins, Hugo Aleixo, Leite da Cunha, Ana Raposo, Marcos Cerqueira, Helena Canhão, Gonçalo Martinho, Francisco Mendes, Cláudia Quinta, José 
Mousinho, Maria Carmo Barbosa, Mafalda Batista, Lúcia Costa, Ana Roxo, Ana Abrantes, Manuel Sousa, Cláudia Vaz and Paulo Felicíssimo, for the identification, selection, randomization and informed consent collection of the patients included in this study. This study is supported by unrestricted grants from the Direção Geral da Saúde and Amgen, which had no role in the design of the study or the writing or review of the paper.

\section{Conflicts of interest None.}

Funding This study was supported by unrestricted grants from the Direção Geral da Saúde and Amgen which had no role in the design of the study, the writing or review of the paper.

\section{References}

1. Hernlund E, Svedbom A, Ivergard M, Compston J, Cooper C, Stenmark J et al (2013) Osteoporosis in the European Union: medical management, epidemiology and economic burden. A report prepared in collaboration with the International Osteoporosis Foundation (IOF) and the European Federation of Pharmaceutical Industry Associations (EFPIA). Arch Osteoporos 8(1-2):136

2. Johnell O (1997) The socioeconomic burden of fractures: today and in the 21 st century. Am J Med 103(2a):20S-25S, discussion 5S-6S

3. Harvey N, Dennison E, Cooper C (2010) Osteoporosis: impact on health and economics. Nat Rev Rheumatol 6(2):99-105

4. Marques A, Mota A, Canhao H, Romeu JC, Machado P, Ruano A et al (2013) A FRAX model for the estimation of osteoporotic fracture probability in Portugal. Acta Reumatol Port 38(2):104-112

5. Kanis JA, Oden A, McCloskey EV, Johansson H, Wahl DA, Cooper C (2012) A systematic review of hip fracture incidence and probability of fracture worldwide. Osteoporos Int: J Established Result Cooperation Eur Found Osteoporos Nat Osteoporos Found USA 23(9):2239-2256

6. Tarricone R (2006) Cost-of-illness analysis. What room in health economics? Health Policy (Amsterdam, Netherlands) 77(1):51-63

7. Strom O, Borgstrom F, Zethraeus N, Johnell O, Lidgren L, Ponzer S et al (2008) Long-term cost and effect on quality of life of osteoporosis-related fractures in Sweden. Acta Orthop 79(2):269280

8. Budhia S, Mikyas Y, Tang M, Badamgarav E (2012) Osteoporotic fractures: a systematic review of U.S. healthcare costs and resource utilization. PharmacoEconomics 30(2):147-170

9. Ferreira LN, Ferreira PL, Pereira LN, Oppe M (2013) EQ-5D Portuguese population norms. Quality of Life Research: an international journal of quality of life aspects of treatment, care and rehabilitation

10. Qu B, Ma Y, Yan M, Wu HH, Fan L, Liao DF et al (2014) The economic burden of fracture patients with osteoporosis in western China. Osteoporos Int: J Established Result Cooperation Eur Found Osteoporos Nat Osteoporos Found USA 25(7):1853-1860

11. Borgstrom F, Zethraeus N, Johnell O, Lidgren L, Ponzer S, Svensson O et al (2006) Costs and quality of life associated with osteoporosis-related fractures in Sweden. Osteoporos Int: J Established Result Cooperation Eur Found Osteoporos Nat Osteoporos Found USA 17(5):637-650

12. Drummond MF (1988) Methods for the economic evaluation of health care programmes: Oxford University

13. Cochran WG (1977) Sampling techniques. New York, Wiley. 98: 259-61

14. Scheaffer R, Mendenhall III W, Ott R, Gerow K (2011) Elementary survey sampling: Cengage Learning

15. Cleves M (2008) An introduction to survival analysis using Stata: Stata Press
16. Osnes EK, Lofthus CM, Meyer HE, Falch JA, Nordsletten L, Cappelen I et al (2004) Consequences of hip fracture on activities of daily life and residential needs. Osteoporos Int: J Established Result Cooperation Eur Found Osteoporos Nat Osteoporos Found USA 15(7):567-574

17. Bonafede M, Espindle D, Bower AG (2013) The direct and indirect costs of long bone fractures in a working age US population. J Med Econ 16(1):169-178

18. Zielinski SM, Bouwmans CA, Heetveld MJ, Bhandari M, Patka P, Van Lieshout EM (2014) The societal costs of femoral neck fracture patients treated with internal fixation. Osteoporos Int: J Established Result Cooperation Eur Found Osteoporos Nat Osteoporos Found USA 25(3):875-885

19. Lambrelli D, Burge R, Raluy-Callado M, Chen SY, Wu N, Schoenfeld MJ (2014) Retrospective database study to assess the economic impact of hip fracture in the United Kingdom. Journal of Medical Economics. 1-9

20. Nikitovic M, Wodchis WP, Krahn MD, Cadarette SM (2013) Direct health-care costs attributed to hip fractures among seniors: a matched cohort study. Osteoporos Int: J Established Result Cooperation Eur Found Osteoporos Nat Osteoporos Found USA 24(2):659-669

21. Sahota O, Morgan N, Moran CG (2012) The direct cost of acute hip fracture care in care home residents in the UK. Osteoporos Int: J Established Result Cooperation Eur Found Osteoporos Nat Osteoporos Found USA 23(3):917-920

22. Borgstrom F, Lekander I, Ivergard M, Strom O, Svedbom A, Alekna V et al (2013) The International Costs and Utilities Related to Osteoporotic Fractures Study (ICUROS)-quality of life during the first 4 months after fracture. Osteoporos Int: J Established Result Cooperation Eur Found Osteoporos Nat Osteoporos Found USA 24(3):811-823

23. Peasgood T, Herrmann K, Kanis JA, Brazier JE (2009) An updated systematic review of health state utility values for osteoporosis related conditions. Osteoporos Int: J Established Result Cooperation Eur Found Osteoporos Nat Osteoporos Found USA 20(6):853-868

24. Hagino H, Nakamura T, Fujiwara S, Oeki M, Okano T, Teshima R (2009) Sequential change in quality of life for patients with incident clinical fractures: a prospective study. Osteoporos Int: J Established Result Cooperation Eur Found Osteoporos Nat Osteoporos Found USA 20(5):695-702

25. Silverman SL (2009) From randomized controlled trials to observational studies. Am J Med 122(2):114-120

26. Vandenbroucke JP, von Elm E, Altman DG, Gotzsche PC, Mulrow CD, Pocock SJ et al (2007) Strengthening the Reporting of Observational Studies in Epidemiology (STROBE): explanation and elaboration. Ann Intern Med 147(8):W163-W194

27. Vassar M, Holzmann M (2013) The retrospective chart review: important methodological considerations. J Educ Eval Health Prof $10: 12$

28. Parsons N, Griffin XL, Achten J, Costa ML (2014) Outcome assessment after hip fracture: is EQ-5D the answer? Bone Joint Res 3(3):69-75

29. van Agt HM, Essink-Bot ML, Krabbe PF, Bonsel GJ (1994) Testretest reliability of health state valuations collected with the EuroQol questionnaire. Soc Sci Med (1982) 39(11):1537-1544

30. Alolabi B, Bajammal S, Shirali J, Karanicolas PJ, Gafni A, Bhandari M (2009) Treatment of displaced femoral neck fractures in the elderly: a cost-benefit analysis. J Orthop Trauma 23(6):442-446

31. Boonen S, Singer AJ (2008) Osteoporosis management: impact of fracture type on cost and quality of life in patients at risk for fracture I. Curr Med Res Opin 24(6):1781-1788

32. Leslie WD, Lix LM, Finlayson GS, Metge CJ, Morin SN, Majumdar SR (2013) Direct healthcare costs for 5 years postfracture in Canada: a long-term population-based assessment. Osteoporos Int: J Established Result Cooperation Eur Found Osteoporos Nat Osteoporos Found USA 24(5):1697-1705 